\title{
New FDA recommendations to speed drug development
}

On 12 January 2006, the US Food and Drug Administration (FDA) released guidance documents to help scientists speed the development of new medical treatments in clinical research, in an effort to accelerate the process by which new drugs are brought to market for potentially serious and lifethreatening diseases of human patients ${ }^{1-3}$.

In the first document, the FDA advises scientists who plan to conduct very early clinical studies in people on how to perform appropriate safety tests and produce small amounts of drugs safely, flexibly, and efficiently ${ }^{4}$. The second document provides guidance on how to comply with current good manufacturing practice (CGMP) requirements for drugs undergoing early (Phase 1) safety studies ${ }^{5}$.
Health and Human Services Secretary Mike Leavitt stated that "Currently, nine out of ten experimental drugs fail in clinical studies because we cannot accurately predict how they will behave in people based on laboratory and animal studies." The new FDA recommendations, he said, "will help more researchers conduct earlier, moreinformed studies of promising treatments so patients have more rapid access to safer and more effective drugs ${ }^{1}$."

According to Janet Woodcock, MD, FDA Deputy Commissioner for Operations, these new guidances will help researchers who conduct small studies to overcome the burdensome requirements for early Phase 1 studies, which previously required such investigators to implement the same procedures as manufacturers who produce and distribute large amounts of medicines $^{1}$

1. FDA. FDA issues advice to make earliest stages of clinical drug development more efficient. (12 January 2006).

2. FDA. Direct final rule. Current good manufacturing practice regulation and investigational new drugs. Federal Register 71(10), 2458-2462 (17 January 2006).

3. FDA. FDA teleconference: steps to advance the earliest phases of clinical research in the development of innovative medical treatments. (12 January 2006).

4. FDA. Guidance for industry, investigators, and reviewers: exploratory IND studies. (January 2006).

5. FDA. Guidance for industry: INDs-approaches to complying with CGMP during Phase 1. (January 2006).

\section{European Union adopts an action plan to improve animal welfare}

On 23 January 2006, the European Union (EU) adopted an action plan of concrete measures for the next five years to protect animal welfare "in all EU sectors and through EU relations with Third countries" by "upgrading minimum standards for animal welfare; promoting research and alternative approaches to animal testing; introducing standardized animal welfare indicators; better informing animal handlers and the general public on animal welfare issues; and supporting international initiatives for the protection of animals ${ }^{1}$."

The Action Plan requested by the European Parliament and the Council specifically aims to:

- Upgrade the minimum standards for animal welfare according to the latest scientific information and public demand, including animal species not now covered by the EU, and proper application and enforcement of these new standards.

- Continue support of research projects on animal welfare, with the possible creation of a European Centre or Laboratory to coordinate, collect, and exchange information on research and activities related to animal welfare, with particulare attention to the "3Rs."

- Create a classification system for animal welfare practices that will distinguish minimum from higher standards of animal welfare.

- Inform and train those in direct contact with animals of the issues and their responsibilities for the proper treatment of animals, and create an "Information Platform for Animal Welfare," to facilitate the exchange of best practices of animal care. Inform and educate EU consumers on the costs and benefits of higher animal welfare standards in farming practices, and introduce improved marketing, labeling and communication strategies to meet this goal.

- Support and initiate international proposals to increase awareness of and consensus on animal welfare issues, and work with the Council of Europe and the World Organization for Animal Health on the health and welfare of animals, and with the World Trade Organization to press for greater acceptance of animal welfare policies.

- Help developing countries plan and implement animal welfare measures, and integrate these into trade agreements.

1. Europa. Improving animal welfare: EU action plan adopted. (23 January 2006). 